\title{
TESTING SYSTEM FOR ANALOG DEVICES DIRECT DIGITAL SYNTHESIZER
}

\author{
Ilia Loskutov", Ivan Shvetsov-Shilovskiy, Dmitry Boychenko \\ National Research Nuclear University MEPhI (Moscow Engineering Physics Institute), 115409, \\ Moscow, Russia
}

\begin{abstract}
The paper is devoted to the setup for controlling and testing of Direct Digital Synthesizer (DDS) Integrated Circuits (ICs). Control and measurement setup is designed on the basis of National Instruments module equipment PXI-4110, PXI-7841R and LabVIEW development environment. Block diagram of the developed system and software structure are depicted as well as test results for several ICs.
\end{abstract}

\section{Introduction}

Different electronic devices often need an IC that generates signals of various frequencies and allows controlling parameters of such a signal [1]. Direct Digital Synthesizer IC can play the role of the generator of this kind. The device produces analog signal by means of generating series of samples in digital form and then converting these to the analog signal using ADC $[2,3]$. The main blocks of DDS are phase accumulator, phase-to-amplitude converter (PAC), DAC and low-pass filter. Block diagram of the simplest DDS IC is presented on Figure 1. Adjustment of the IC's parameters (settling the desired frequency, phase, amplitude, form etc.) is made by means of special build-in registers. These registers are available for read and write to via different interface protocols, e.g. SPI.

One of the features of DDC ICs is high frequency setting resolution and high precision of frequency rendering. Some modern digital synthesizers are capable of generating signals with frequency of $1 \mathrm{~Hz}$ up to $400 \mathrm{MHz}$ with the step size of $0.00001 \mathrm{~Hz}$.

At the moment DDS are applied in two main areas: signal generation in communication systems and signal analysis in industrial and biomedical applications.

While developing devices of various purposes, often raises an aim to test the functionality of its separate components. Thus, for example, it is necessary to test the functionality of the DDS ICs. This paper concerns the design of the control and measurement setup $[4,5]$ for Analog Devices DDS ICs.

\footnotetext{
Corresponding author: iolos@spels.ru
} 


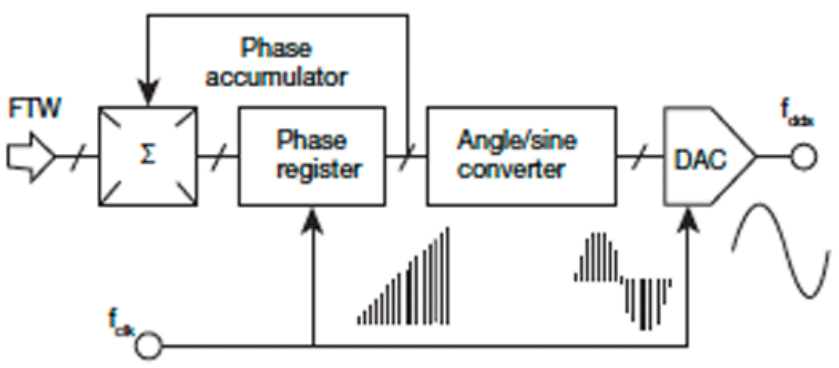

Figure 1. DDS block diagram.

\section{Device under test and setup requirements}

Devices Under Test (DUTs) were AD9851, AD9910 and AD9912 Analog Devices DDS IC.

$\mathrm{AD} 9851$ is a device that is capable to operate in voltage supply range from $2.7 \mathrm{~V}$ to 5.25 $\mathrm{V}$; clock frequency can be up to $180 \mathrm{MHz}$. AD9851 also includes a high-speed 10-bit DAC.

AD9910 and AD9912 are ICs with integrated 14-digit DAC; voltage lies within range of $1.8 \mathrm{~V}$ to $3.3 \mathrm{~V}$; output frequency is up to $400 \mathrm{MHz}$ [6].

One of the distinctive features of the abovementioned ICs is a similar SPI communication interface that has made possible to design universal control and measurement setup.

\section{Solution}

Control and measurement system was designed on the basis of automated setup that included National Instruments PXI module devices and software developed in LabVIEW development environment [7-14].

Hardware included following components:

- PXI-1033: 5-slot chassis (data transfer rate of $110 \mathrm{MB} / \mathrm{s}$, noise less than $38 \mathrm{~dB}$, power $400 \mathrm{~W}$ ).

- PXI-4110: programmable power supply (three channels with a voltage range from 0 $\mathrm{V}$ to $6 \mathrm{~V}$, from $0 \mathrm{~V}$ to $20 \mathrm{~V}$ and from $0 \mathrm{~V}$ to $-20 \mathrm{~V}$ accordingly).

- PXI-7841R: multifunction input/output board (based on Virtex-5R FPGA, 96 bidirectional digital ports, 8 analog inputs, 8 analog outputs) [7].

- universal communication PCB.

- $\mathrm{PCB}$ with the IC.

- Agilent 54642D oscilloscope.

PXI-4110 module allowed controlling supply voltage and measuring supply current in range up to $1 \mathrm{~A}$ and with precision of $0.02 \mathrm{~mA}$.

Desired communication interface between test equipment and ICs was implemented by means of the PXI-7841R module. PXI-7841R embedded Programmable Logic Device (PLD) has a high operation rate; base frequency is $40 \mathrm{MHz}$ that can be altered due to buildin Phase-Locked Loop (PLL). The module also includes analog lines (8 analog inputs and 8 analog outputs). This gives the opportunity to measure logical output signal level with precision of $0.3 \mathrm{mV}$.

Universal adapter PCB has pins for all PXI-7841 digital and analog signal lines and channels of PXI-4110 power supply module. 
DUT PCBs were developed for each DDS type according to the reference schematic presented in technical documentation. The photo of the universal communication board and printed circuit board for testing is shown on Figure 2.

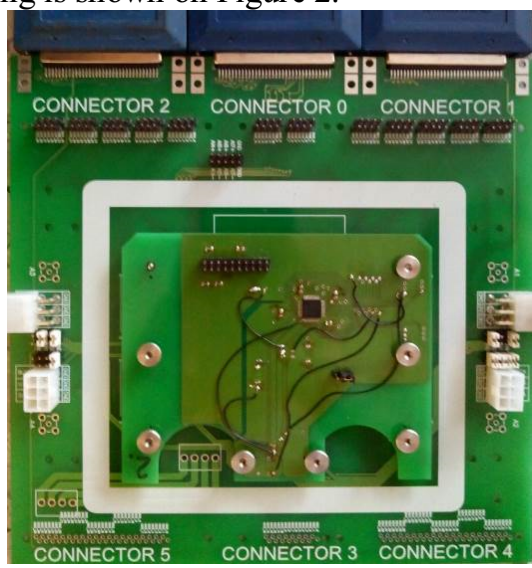

Figure 2. Appearance of the universal communication board and board with the PCB.

Agilent 54642D oscilloscope was used to control output signal's frequency. Block diagram of the measurement setup is presented on Figure 3.

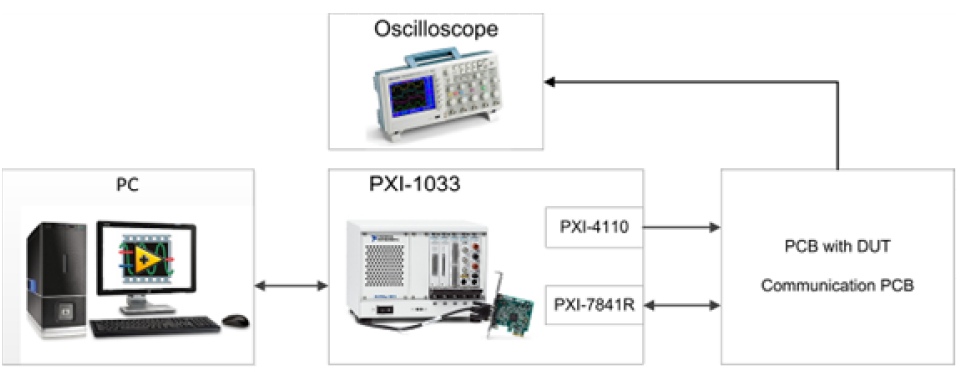

Figure 3. Hardware structure with DUT.

Software part was made in LabVIEW 2013 development environment.

This software allowed controlling PXI-4110 and PXI-7841R modules, as well as create user interface.

The program was divided into two main parts: HOST part and FPGA part. The first one was run on PC with relatively slow execution rate and provided the automatization of testing process; it set supply voltage levels, logged the results and initialized the FPGA module [8].

The second part was programmed into PLD and had a high operation rate. Its task was to set the clock frequency, transmit and receive data [9-18].

To run the DDS IC one often needs a reference frequency; PXI-7841R module allowed to generate such high-frequency periodic signal. Block diagram of the Virtual Instrument (VI) that is responsible for frequency generation is shown on Figure 4 [9]. 


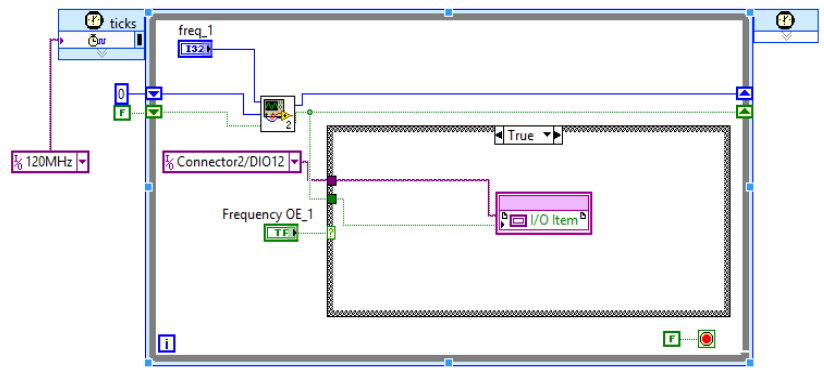

Figure 4. PXI-7841R frequency generator block diagram.

Prior to test procedure user is asked for communication interface parameters, such as register address, byte number, transfer direction, bits order and timing parameters. The example of write timing diagram is presented on Figure 5.

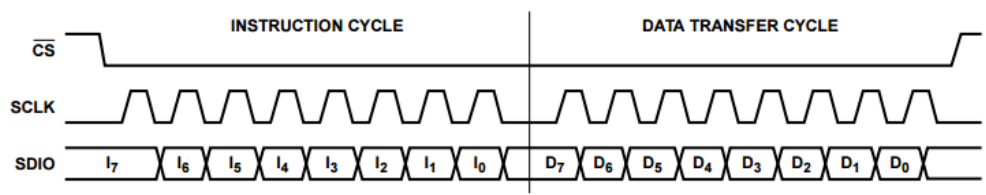

Figure 5. Data write timing diagram for AD9910 IC.

Low level on CS indicates the beginning of data communication. SDIO line is used to transfer 8-bit address first and then 8 bits of data; the state of the line is latched at the rising edge on the SCLK line. The transmission ends after sending a high level on CS.

Block diagram of the LabVIEW virtual instrument that implements sending the data via SPI interface is presented on Figure 6. One should notice the use of cluster data type, which allows fast digital lines reconfiguration.

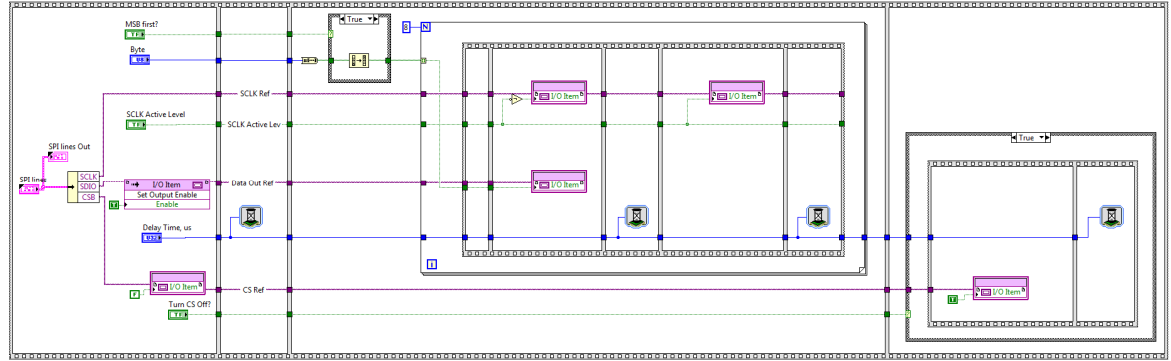

Figure 6. Block diagram of the VI that sends one byte via SPI communication interface.

Test procedure consisted of the following steps:

- IC current supply control by means of ammeter embedded in NI PXI-4110 module.

- Output logic levels control.

- Writing and reading the control registers.

- Taking measurements of the output frequency with certain base frequency division and multiplication coefficients. An example of the output signal is presented on Figure 7. 


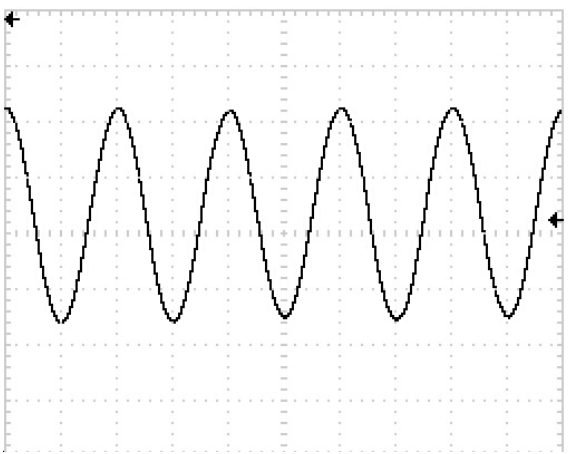

Figure 7. Waveform of the output signal. Scales: 1ns/div; 1V/div.

Convenient user interface (Figure 8) made the system easy to use.

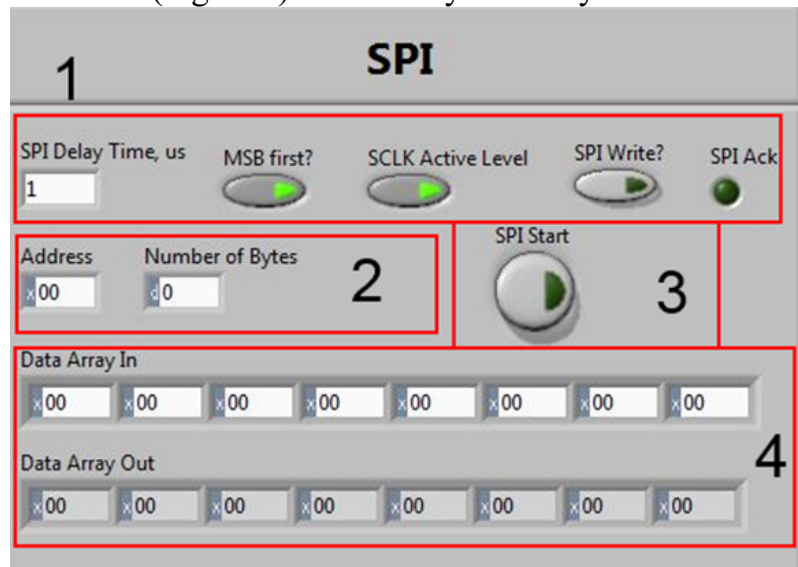

Figure 8. User interface of the control system:1 - primary interface settings; 2 - controls for entering register address and byte number to receive or transmit; 3 - communication start button; 4 - received and transmitted data.

\section{Conclusions}

AD9851, AD9910, AD9912 ICs were successfully tested by means of foregoing measurement setup. Measurement setup has made possible to fulfill the functional and parametrical testing. It is planned to add several other standard interface libraries such as 1wire, $\mathrm{I} 2 \mathrm{C}$ etc. that will allow controlling and testing other devices.

\section{Acknowledgements}

The work was performed as part of the grant of Russian Ministry of Education and MEPhI № 14.578.21.0075.

\section{References}

[1] D. Wang, J. Dong and S. Xiao, MATEC Web of Conferences 22, 02005 (2015) doi: $10.1051 /$ matecconf/20152202005 
[2] N. E. Aristova, A. Y. Borisov, A. I. Tararaksin, L. N. Kessarinskiy, A. V. Yanenko, 2015 International Siberian Conference on Control and Communications (SIBCON), 7146984 (2015) doi: 10.1109/SIBCON.2015.7146984

[3] E. Murphy, C. Slattery, Analog Dialogue 38, 1 (2005)

[4] W. Fan, Y. An, D. Liu and S.Guan, MATEC Web of Conferences 40, 07002 (2016) doi: 10.1051/matecconf/20164007002

[5] Hang Bai, Yunlai Huang, Di Lu, Ping Lai and Hongzhi Fan, MATEC Web of Conferences 40, 07006 (2016) doi: 10.1051/matecconf/20164007006

[6] Analog Devices URL: http://www.analog.com/ru/products/clock-and-timing/directdigital-synthesis.html

[7] PXI Platform - National Instruments URL: http://www.ni.com/pxi/

[8] V. A. Marfin, P.V. Nekrasov, O. A. Kalashnikov, K. A. Kagirina, 2015 International Siberian Conference on Control and Communications (SIBCON), 7147142 (2015) doi: 10.1109/SIBCON.2015.7147142

[9] I. O. Loskutov, A. B. Karakozov, P.V. Nekrasov, A.Y. Nikiforov, 2015 International Siberian Conference on Control and Communications (SIBCON), 7147128 (2015) doi: 10.1109/SIBCON.2015.7147128

[10] M. P. Belova, D. V. Pechenkina, A. Y. Borisov, L. N. Kessarinskiy, D.V. Boychenko, 2015 International Siberian Conference on Control and Communications (SIBCON), 7146995 (2015) doi: 10.1109/SIBCON.2015.7146995

[11] I. I. Shvetsov-Shilovskiy, P.V. Nekrasov, A.V. Ulanova, A. A.Smolin, A. V. Sogoyan, 2015 International Siberian Conference on Control and Communications (SIBCON), 7147282 (2015) doi: 10.1109/SIBCON.2015.7147282

[12] A. B. Boruzdina, A. A. Orlov, A. V. Ulanova, N. G. Grigor'ev, A.Y. Nikiforov, 2015 International Siberian Conference on Control and Communications (SIBCON), 7147007 (2015) doi: 10.1109/SIBCON.2015.7147007

[13] G. G. Davydov, A. S. Kolosova, L. N. Kessarinskiy, D.V. Boychenko, 2015 International Siberian Conference on Control and Communications (SIBCON), 7147094 (2015) doi: 10.1109/SIBCON.2015.7147094

[14] N. E. Aristova, A. I. Tararaksin, L. N. Kessarinskiy, A. Y. Borisov, A.Y. Nikiforov, 2015 International Siberian Conference on Control and Communications (SIBCON), 7146985 (2015) doi: 10.1109/SIBCON.2015.7146985

[15] N. E. Aristova, A. Y. Borisov, A. I. Tararaksin, L. N. Kessarinskiy, and A. V. Yanenko, 2015 International Siberian Conference on Control and Communications (SIBCON), 7146984 (2015) doi: 10.1109/SIBCON.2015.7146984

[16] A.V. Demidova, A. Y. Borisov, L. N. Kessarinskiy, and D.V. Boychenko, 2015 International Siberian Conference on Control and Communications (SIBCON), 7147036 (2015) doi: 10.1109/SIBCON.2015.7147036

[17] V.V. Elesin, A. G. Kuznetsov and D. I. Sotskov, 2014 24th International Crimean Conference Microwave and Telecommunication Technology (CriMiCo), 6959664 (2014) doi: 10.1109/CRMICO.2014.6959664

[18] P. Nekrasov, A. Demidov, and O. Kalashnikov, Instruments and Experimental Techniques 52, 196 (2009) doi: 10.1134/S0020441209020092 